\title{
Determination of the elemental distribution in human joint bones by SR micro XRF
}

\author{
N. Zoeger, ${ }^{1}$ C. Streli, ${ }^{1}$ P. Wobrauschek, ${ }^{1}$ C. Jokubonis, ${ }^{1}$ G. Pepponi, ${ }^{2}$ P. Roschger, ${ }^{3}$ \\ J. Hofstaetter, ${ }^{3,4}$ A. Berzlanovich,, ${ }^{5,6}$ D. Wegrzynek, ${ }^{7,8}$ E. Chinea-Cano, ${ }^{7}$ A. Markowicz,, ${ }^{7,8}$ \\ R. Simon ${ }^{9}$ and G. Falkenberg ${ }^{10}$
}

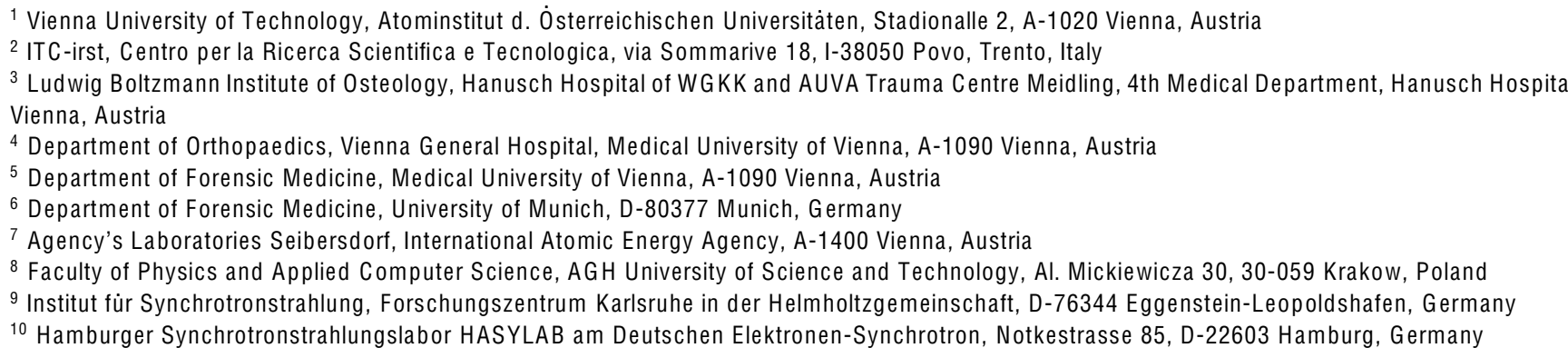

In humans the toxic trace element lead $(\mathrm{Pb})$ mainly accumulates in the skeletal tissue where it resides for a long period. Although $\mathrm{Pb}$ is known to play a role in bone and cartilage diseases, the distribution of $\mathrm{Pb}$ in these tissues is mostly unknown. Therefore synchrotron-radiation-induced micro $\mathrm{x}$-ray fluorescence analysis (SR m-XRF) in various geometries was used to determine the distributions of $\mathrm{Pb}, \mathrm{Ca}, \mathrm{Zn}$ and $\mathrm{Sr}$ at the cartilage-bone interface in human femoral heads and patellae. SR m-XRF results were matched with backscattered electron (BE) images providing information on structural features of the tissue. Conventional $\mathrm{SR} \mathrm{m}$-XRF at HASYLAB beamline $\mathrm{L}$ showed that $\mathrm{Pb}$ mostly accumulates in a zone of some micrometers around the transition between non-calcified and calcified cartilage. However, the relatively large sample thickness did not allow more precise conclusions. Exploiting the 3D capabilities of confocal SR m-XRF and SR microfluorescence tomography at ANKA Fluo-Topo beamline and HASYLAB beamline L, the spatial resolution could be improved and a highly specific accumulation of $\mathrm{Pb}$ at the tidemark, the calcification front between non-calcified and calcified cartilage, was detected. It was found that $\mathrm{Pb}$ and $\mathrm{Zn}$ accumulation coincide at the tidemark. Since the tidemark plays an important role in osteoarthritis, the results may strengthen other authors' conclusions that $\mathrm{Pb}$ is associated with this joint disease. Although offering less spatial resolution when compared to micro-tomography, confocal SR m-XRF is best suited for such studies. It facilitates the comparison of element maps with other imaging techniques like BE imaging. Copyright 2007 John Wiley \& Sons, Ltd.

\section{INTRODUCTION}

Lead $(\mathrm{Pb})$ is a toxic heavy metal that is taken up by humans mainly from air and food. Although much progress has been made in limiting $\mathrm{Pb}$ exposure, primarily through the elimination of leaded gasoline, workplace exposures and leaded pipes, most adults have already accumulated a substantial body burden of $\mathrm{Pb} .^{1,2} \mathrm{~Pb}$ is predominantly accumulated in the skeleton, where approximately $95 \%$ of the total body burden of $\mathrm{Pb}$ is present. ${ }^{3}$ Since the estimated half-life of $\mathrm{Pb}$ in calcified tissue is up to 20 years, ${ }^{4}$ bone $\mathrm{Pb}$ reflects long-term exposure and has therefore been extensively studied by in vivo $\mathrm{x}$-ray fluorescence analysis (XRF) throughout the last 30 years. ${ }^{5}$ Diseases or states with increased bone turnover, such as osteoporosis, pregnancy,

${ }^{\mathrm{E}}$ Correspondence to: N. Zoeger, Vienna University of Technology, Atominstitut, Stadionalle 2, A-1020 Vienna, Austria.

E-mail: zoeger@ati.ac.at hyperthyroidism and hyperparathyroidism, are associated with increased mobilization of $\mathrm{Pb}$ from the skeleton. ${ }^{6-8}$ It has been reported that $\mathrm{Pb}$ plays a role in osteopenia ${ }^{9,10}$ and inhibits fracture healing. ${ }^{11}$ Moreover, intra-articular lead has shown to lead to osteoarthritic changes in the knee joint in humans ${ }^{12}$ as well as in experimental animal models. ${ }^{13,14}$ Therefore, bone is not only an endogenous source of $\mathrm{Pb}$, but osteoblasts and chondrocytes seem to be important target cells for the toxic effects of $\mathrm{Pb} .{ }^{15}$ However, surprisingly little is known about how $\mathrm{Pb}$ is distributed in bone and cartilage at the microscopic level. Previous studies on the distribution of $\mathrm{Pb}$ in bone using different techniques, such as atomic absorption spectroscopy (AAS), ${ }^{3,16,17}$ proton induced X-ray emission (PIXE), ${ }^{18,19}$ inductively coupled plasma mass spectrometry (ICPMS) ${ }^{20}$ and synchrotron-radiationinduced x-ray emission (SRIXE), ${ }^{21}$ were mainly focussed on differences between compact and trabecular bone and have not been applied to the bone-cartilage interface. Therefore 
the purpose of this study was to determine the spatial distribution of $\mathrm{Pb}$ in the chondral and subchondral regions from normal humans, using synchrotron-radiation-induced micro x-ray fluorescence analysis (SR -XRF) in various geometries. Exploiting the multi-element detection capability of energy dispersive XRF, data on the distribution of other elements $(\mathrm{Ca}, \mathrm{Zn}, \mathrm{Sr})$ present in the bone samples were obtained simultaneously.

\section{EXPERIMENTAL}

\section{Samples and sample preparation}

Four femoral heads and three patellas were harvested from five (three female, two male) randomly selected forensic autopsies. All individuals died of illnesses of the heart or accidents and had no history of metabolic bone disease or $\mathrm{Pb}$ exposure. In two cases, one femoral head and one patella were taken from the same individual (paired autopsies). In two cases one single femoral head and in one case a single patella was harvested. The age of the subjects ranged from 48 to 65 years. The study was approved by the Institutional Ethical Review Board of the Department of Forensic Medicine of the Medical University of Vienna.

Tissue sections of $5 \mathrm{~mm}$ thickness were cut perpendicular to the articular surface from the central region of patellas as well as from the superior, weight-bearing region of the femoral heads. Samples were fixed in $70 \%$ ethanol, dehydrated through a series of alcohol, and embedded in polymethylmethacrylate (PMMA). ${ }^{22}$ After trimming the sample to dimensions of 15 ð 15 ð $5 \mathrm{~mm}$, surfaces of the PMMA blocks were polished using a diamond suspension and carbon coated for backscattered electron (BE) imaging.

Samples that were analysed by both conventional SR XRF and confocal SR -XRF were prepared as 200- $\mu \mathrm{m}$ thick slices by low-speed diamond saw (Buehler Isomed, Lake Pluff, USA) cutting.

After SR -XRF analysis in the conventional mode, one of the 200- $\mu \mathrm{m}$ thick patella samples was prepared for combined $\mathrm{x}$-ray absorption and fluorescence tomography. By lowspeed diamond saw cutting the size of the sample has been reduced from $15 \mathrm{~mm}$ ð $15 \mathrm{~mm}$ ð $200 \mu \mathrm{m}$ to the dimensions of about $2 \mathrm{~mm}$ ð $4 \mathrm{~mm}$ ð $200 \mu \mathrm{m}$. Then the remaining piece was clamped between two panels of Plexiglas and ground to a size of $300 \mu \mathrm{m} ð 4 \mathrm{~mm}$ ð $200 \mu \mathrm{m}$. The specimen was then rinsed with pure alcohol and glued to a thin graphite tip.

All samples were prepared in a way to contain noncalcified cartilage, calcified cartilage, tidemark as well as subchondral bone.

\section{Backscattered electron imaging}

$\mathrm{BE}$ imaging is a validated technique to visualize the mineralized phase of cartilage and bone tissue quantitatively..$^{23-25}$ It is based on the detection of BEs from the sample surface in a scanning electron microscope. The intensity of the $\mathrm{BE}$ signal is proportional to the average atomic number of the target material. In the case of mineralized tissue, which is mainly composed of an organic matrix (average atomic number $Z 3 / 46$ ) and of mineral particles rich in calcium ions ( $Z$ D 20), the BE image contrast is therefore dominated by the calcium content of the tissue. Areas in the BE image with bright gray levels reflect mineralized matrix with high $\mathrm{Ca}$ contents, whereas areas with dark grey levels indicate low mineral density.

The BE images provide the spatial distribution of mineralization density at the sectioned tissue surface with an information depth about $1 \mu \mathrm{m}$ (Fig. 2(a)). Areas of mineralized cartilage have a more homogeneous intrinsic structure and have a higher degree of mineralization than bone. Mineralized cartilage can therefore be identified by its higher grey level in the BE images. The tidemark is a typical narrow seam of gradually increasing mineral content at the border between non-calcified and calcified articular cartilage. ${ }^{24,25}$ Younger bone packets have a characteristic lower mineral content (lower grey level in BE images) than the older, more mature bone packets (higher grey level in BE images). ${ }^{26}$

Because of this, BE imaging provides information on the histological features of the analysed bone sections, and was therefore performed on all samples prior to -XRF measurements.

A digital scanning electron microscope (DSM 962, Zeiss, Oberkochen, Germany) equipped with a four-quadrant semiconductor BE detector was employed. The microscope was operated at an acceleration voltage of $20 \mathrm{kV}$, a working distance of $15 \mathrm{~m}$ and a probe current of $110 \mathrm{pA}$. Images at a series of magnifications 12 to $500 ð$ were acquired.

\section{SR m-XRF}

SR -XRF measurements in various modes were performed at two different synchrotron radiation facilities to study the (trace) elemental distribution at the interface between noncalcified and calcified tissue in slices of human joint bones. Experiments were carried out at beamline L at HASYLAB, Hamburg, Germany, and at the Fluo-Topo beamline at ANKA, Karlsruhe, Germany. At HASYLAB beamline L, conventional and confocal SR -XRF were used, whereas at ANKA Fluo-Topo beamline analyses were performed in confocal and tomographic modes.

The layout of the general set-up that was used throughout all the experiments is shown in Fig. 1. A detailed description of the individual set-ups is given below.

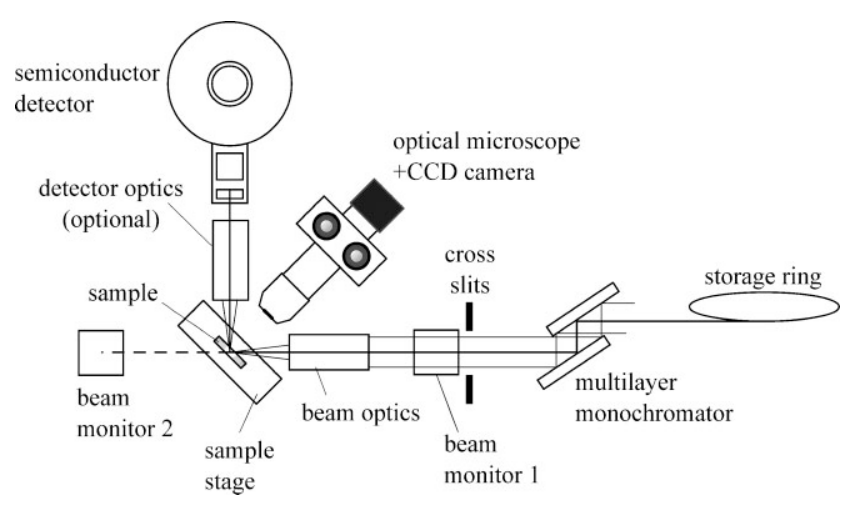

Figure 1. Scheme of a typical set-up for SR- XRF. 


\section{Conventional and confocal $S R \quad-X R F$ analysis}

At HASYLAB, beamline $\mathrm{L}$ a Ni/C multilayer was chosen to select photons with suitable energy from the continuous spectrum produced by the $1.2 \mathrm{~T}$ bending magnet. For all the conducted experiments the energy of the primary photons was set to be around $17.5 \mathrm{keV}$. After passing a cross-slit system and an ionization chamber for beam monitoring, the primary $\mathrm{x}$-ray beam was focussed by means of a polycapillary half lens (XOS, X-Ray Optical Systems, Albany, New York). With this optics it was possible to concentrate the beam to a spot size of $13 \mu \mathrm{m}$ FWHM. At the focal distance of the capillary (about $5 \mathrm{~mm}$ ) the sample was mounted on a motor driven $X Y Z$ sample stage with a maximum scanning range of $30 \mathrm{~mm}$, capable of moving the specimen in incremental steps of $1 \mu \mathrm{m}$ relative to the incident beam.

In the case of conventional -XRF, the fluorescence photons from the sample were detected by a $\mathrm{Si}(\mathrm{Li})$ semiconductor detector with $80 \mathrm{~mm}^{2}$ active area, $4 \mathrm{~mm}$ crystal thickness and a $12 \mu \mathrm{m}$ Be window (Gresham Sirius 80). In order to avoid unwanted detector artefacts and to achieve a blank spectrum free of any characteristic lines, the standard $\mathrm{Pb}$ shielding of the detector was replaced by a Mo detector cap of $3 \mathrm{~mm}$ diameter. To suppress spectral contributions from the housing of the beam optics, the exit of the polycapillary was also shielded by a small Mo cap (diameter about $1 \mathrm{~mm}$ ). To make optimal use of the linear polarization of the incoming beam, the detector was mounted in the orbital plane of the storage ring and the angle between beam and detector was fixed at $90^{\circ}$. The angle between the beam and the sample as well as the sample and the detector was fixed at $45^{\circ}$ each. With this set-up, minimum detection limits down to about $10 \mathrm{ng} / \mathrm{g}$ can be achieved in biological materials. ${ }^{27}$ For visually controlling the beam position, an optical microscope coupled to a high-resolution CCD camera was used. The angle between the beam and the microscope as well as the microscope and the detector was $45^{\circ}$ each, thereby having the microscope looking perpendicularly on the sample surface. Analyses in the conventional mode were typically performed as line scans starting in non-calcified cartilage, including the zone of calcified cartilage as well as subchondral bone. The distance between the measurement points was chosen to be $10 \mu \mathrm{m}$ and the counting time per point was set to $40-100 \mathrm{~s}$. The acquired spectra were processed using the 'microXRF' software package available at the beamline or the AXIL software from the QXAS ${ }^{28}$ package for peak deconvolution and subtraction of the radiation background. Subsequently, plotting the obtained intensities $v s$ the relative sample position gives the distribution of each element along the line scan. In order to visualize simultaneously the distribution of Ca showing high intensities and the trace elements with low intensities, the intensity profile for each element was normalized to its maximum value. With this set-up, 11 line scans across articular cartilage and subchondral bone were performed on all the samples of femoral head and patella. To correlate the distribution of chemical elements with the micro-structural features of bone, we overlaid data obtained from SR -XRF line scans with BE images defining the tidemark, as well as the interface between calcified cartilage and subchondral bone.
For confocal SR -XRF analysis at HASYLAB beamline $\mathrm{L}$, the existing conventional -XRF set-up was extended by inserting a second polycapillary half lens (XOS, X-Ray Optical Systems, Albany, New York) as detector optics (Fig. 1). To be able to adjust the confocal geometry, the x-ray optics was directly attached to the detector snout by a Plexiglas holder and the detector was mounted on a motordriven $X Y Z$ table. The whole alignment procedure, as well as the characteristics of the set-up, has been described in detail by Janssens et al. ${ }^{29}$ In short, to achieve an overlap of the focal spots of the two optics, a bulk specimen was mounted at the focus of the beam optics. After that, the detector was sequentially scanned for each coordinate of the XYZ table while the other two remained constant. This procedure was iteratively repeated for the three directions until a maximum in the inspected fluorescence line was reached. To facilitate the alignment and to have the highest possible stability of the set-up the $\mathrm{Si}(\mathrm{Li})$ detector, which was used in conventional geometry, was replaced by a silicon drift detector (SDD) (Radiant VORTEX). Since no liquid nitrogen cooling is required for this detector, it is much lower in weight and therefore easier to adjust. By scanning a thin $\mathrm{W}$ wire and a 4- $\mu \mathrm{m}$ Au foil, the detection volume, defined by the focal overlap of the two optics, was characterized to be 20 ð 14 ð $22 \mu \mathrm{m}^{3}$ (lateral ð height ð depth).

The principle of the confocal SR -XRF set-up at ANKA, Fluo-Topo beamline is similar to the one installed at HASYLAB. Here a $\mathrm{W} / \mathrm{B}_{4} \mathrm{C}$ multilayer was used to monochromatize the primary photons at $17 \mathrm{keV}$. Two polycapillary half lenses (XOS, X-Ray Optical Systems, Albany, New York) with characteristics comparable to the ones at HASYLAB constitute the confocal detection volume. Characterization of this set-up with the $\mathrm{W}$ wire and the $4 \mu \mathrm{m} \mathrm{Au}$ foil gave a volume of 18 ð 12 ð $19 \mu \mathrm{m}^{3}$ (lateral $ð$ height $ð$ depth). Although not used during the described experiments, the -XRF spectrometer at ANKA offers the possibility to perform analyses under vacuum conditions, which results in a slightly different set-up when compared to the one at HASYLAB. The cross-slits, the beam monitors, the two half lenses and the sample stage are mounted in a vacuum tank. The optical microscope and the semiconductor detector (Oxford Pentafet $30 \mathrm{~mm}^{2} \mathrm{Si}(\mathrm{Li})$ Detector, 8 um Be window, e2v (formerly: Gresham) 'Titan' Digital Signal Processor) are located outside the chamber. ${ }^{30}$ The microscope objective and the detector snout are brought to the chamber via a vacuum feedthrough, and are therefore more or less fixed in their positions. In order to realize the confocal -XRF set-up, the detector optics was not directly mounted to the detector, but on a separate $X Y Z$ stage about $5 \mathrm{~mm}$ in front of the detector window. To facilitate sample loading, when measuring under vacuum conditions, the system is equipped with a sample changer capable of holding eight samples.

All measurements in confocal geometry were typically performed as area scans in the range of 200 $200-500$ ð $500 \mu \mathrm{m}^{2}$ with incremental steps of $10 \mu \mathrm{m}$ in each direction and measurement times of 5-8 s per pixel at both synchrotron radiation facilities. The $3 \mathrm{D}$ capabilities (depth resolution) of the confocal measuring mode were exploited to suppress 
spectral contributions from large sample depths and to detect fluorescence signals only from the first few micrometers of the sample. Subsequent to the measurement, the single spectra of a scan were processed by AXIL peak-fitting in the batch mode. Elemental maps from fluorescence data were generated by a custom-made software and matched with BE images.

In total, 12 area scans on three of the four femoral heads and two of the three patellas, previously analysed with conventional -XRF, were performed in the confocal geometry.

For one patella sample the measurement was extended to a 3D-scan. The elemental distribution was studied in a sample volume of 200 ð 200 ð $160 \mu \mathrm{m}^{3}$ (lateral ð lateral ð depth) with a step size of $10 \mu \mathrm{m}$ in each direction and counting time of $5 \mathrm{~s}$ per voxel. The $\mathrm{x}$-ray peak data, obtained after spectrum processing, were converted to 8-bit greyscale images for each measured slice in depth. From these images, the elementspecific 3D volumes were rendered using the visualization software for tomographic imaging.

\section{SR -fluorescence tomography}

To perform combined fluorescence-absorption tomography measurements at the cartilage-bone interface the microtomography system designed by the XRF Group Instrumentation Unit of the IAEA Seibersdorf Laboratories Austria ${ }^{31}$ was installed at the Topo hutch of the Fluo-Topo beamline at ANKA, Karlsruhe, Germany. ${ }^{32}$ The system comprises a motorized $X Y Z /$ translation/ rotation stage allowing lateral scans of the sample as well as a sample rotation by $360^{\circ}$ necessary for fluorescence tomography. On top of the stage a compact $X Y$ table was mounted to manually correct for sample wobbling. A W/ $\mathrm{B}_{4} \mathrm{C}$ multilayer monochromator was used to provide a monochromatic synchrotron $\mathrm{x}$-ray beam at $16.5 \mathrm{keV}$. Focusing of the beam (beam size about $5 \mu \mathrm{m}$ ) was performed by means of a compound refractive lens (CRL), offering the required pencil-beam geometry for x-ray fluorescence -tomography. Both the multi-layer monochromator and the CRL were provided by ANKA. A fast SDD with a shaping time of $250 \mathrm{~ns}$ operating in continuous discharge mode (Ketek $\mathrm{GmbH}$, München, Germany) and allowing acquisition at high count rates was placed behind the sample to collect photons from the transmitted beam. A Si(Li) semiconductor detector (active area $80 \mathrm{~mm}^{2}$, thickness $3 \mathrm{~mm}$, FWHM D $160 \mathrm{eV}$ at $5.9 \mathrm{keV}$, Link/Oxford Instruments, UK) for recording the fluorescence photons was mounted in the orbital plane perpendicular to the incoming beam. The data acquisition system consisted of three multi-channel analysers for collecting transmitted photons and fluorescence photons and monitoring the incident beam (ionization chamber), and a dedicated software package (SPECTOR-LOCATOR). ${ }^{33}$

$\mathrm{X}$-ray fluorescence and $\mathrm{x}$-ray absorption sinograms for a slice of the patella sample were simultaneously recorded by measuring 64 equidistant (step size D $15.2 \mu \mathrm{m}$ ) lateral points at 64 angles between $0^{\circ}$ and $360^{\circ}$ (angle increment $\mathrm{D} 5.6^{\circ}$ ) at a fixed height. While the measuring time for the fluorescence detector was set to $5 \mathrm{~s}$ per pixel, the acquisition time for the transmission detector and the beam monitor was chosen to be $3 \mathrm{~s}$. From the fluorescence intensities obtained by automatically fitting the 4096 spectra, flux-normalized sinograms for $\mathrm{Ca}, \mathrm{Zn}, \mathrm{Sr}$ and $\mathrm{Pb}$ were created. The absorption sinogram was generated from the total count rate measured by the SDD. Reconstruction of the element-specific images and the transmission image of the measured sample slice was performed by means of filtered back projection (FBP). ${ }^{34}$ Software for the FBP has been developed under the Lab VIEW 6.1 environment.

\section{RESULTS AND DISCUSSION}

\section{Conventional SR m-XRF}

Eleven -XRF line scans across cortical bone were performed on seven slices from femoral head and patella. A representative result obtained from a -XRF line scan in a patella sample is shown in Fig. 2. The performed scan started in the non-calcified cartilage (I) and included the tidemark (II), the zone of calcified cartilage (III) and subchondral bone (IV). By comparing the elemental distributions of $\mathrm{Ca}, \mathrm{Zn}, \mathrm{Sr}$ and $\mathrm{Pb}$ (Fig. 2(b)) with the BE image (Fig. 2(a)), it is obvious that no significant characteristic $x$-ray intensities of these elements were detected in the zone of non-calcified cartilage, far away from the tidemark. If the obtained fluorescence profiles are overlaid with the BE images, one can see that $\mathrm{Ca}$ and $\mathrm{Sr}$ are almost constant over the whole region of the calcified tissue (i.e. calcified cartilage and subchondral bone). Ca reaches its maximum intensity values at the calcification front (tidemark) of the bone sample (position B in Fig. 2(a)). In the transition zone to the calcified cartilage (around the tidemark), a strong increase of the $\mathrm{Zn}$ and $\mathrm{Pb}$ intensities is observed which decays rapidly in the region of calcified cartilage (after $150 \mu \mathrm{m}$ ). Interestingly, the maximum intensities of $\mathrm{Zn}$ and $\mathrm{Pb}$ coincide at the same position (A in Fig. 2(a)), $40 \mu \mathrm{m}$ before the calcification front. These findings of the coincidence of $\mathrm{Zn}$ and $\mathrm{Pb}$ were highly consistent for all the performed line scans. However, the positions of maximum intensities were found to be $0-150 \mu \mathrm{m}$ before the calcification front, depending on the sample analysed. As already discussed in a previous paper, ${ }^{35}$ the local shift between the intensity maxima of the individual line profiles might be a consequence of the large sample thickness when compared to beam diameter $(13 \mu \mathrm{m})$. The element- and matrix-specific information depths for different characteristic x-rays (e.g. $40 \mu \mathrm{m}$ for $\mathrm{Ca}$ and $600 \mu \mathrm{m}$ for $\mathrm{Sr}$ ) together with the measurement geometry are limiting factors in terms of spatial resolution and complicate the correlation of fluorescence intensities to local bone regions. One way to overcome the difficulties would be the preparation of sample slices with a thickness in the range of the beam diameter. Since this is not easily accomplishable, owing to the brittleness of the sample material, -XRF techniques with 3D capabilities have to be considered in order to unfold elemental distributions and structural features of the specimen.

However, on comparing the obtained fluorescence intensities in the transition zone and the subchondral bone (position 200-350) one can see that $\mathrm{Pb}$ and $\mathrm{Zn}$ intensities are enhanced around the tidemark by about a factor of 10 and 2.5, respectively. By calculating the intensity ratios for all the 11 line scans performed, we found average enhancement factors of $13 \check{s} 3.2$ for $\mathrm{Pb}$ and $3.2 \check{\mathrm{s}} 0.8$ for $\mathrm{Zn} .^{36}$ 
(a)
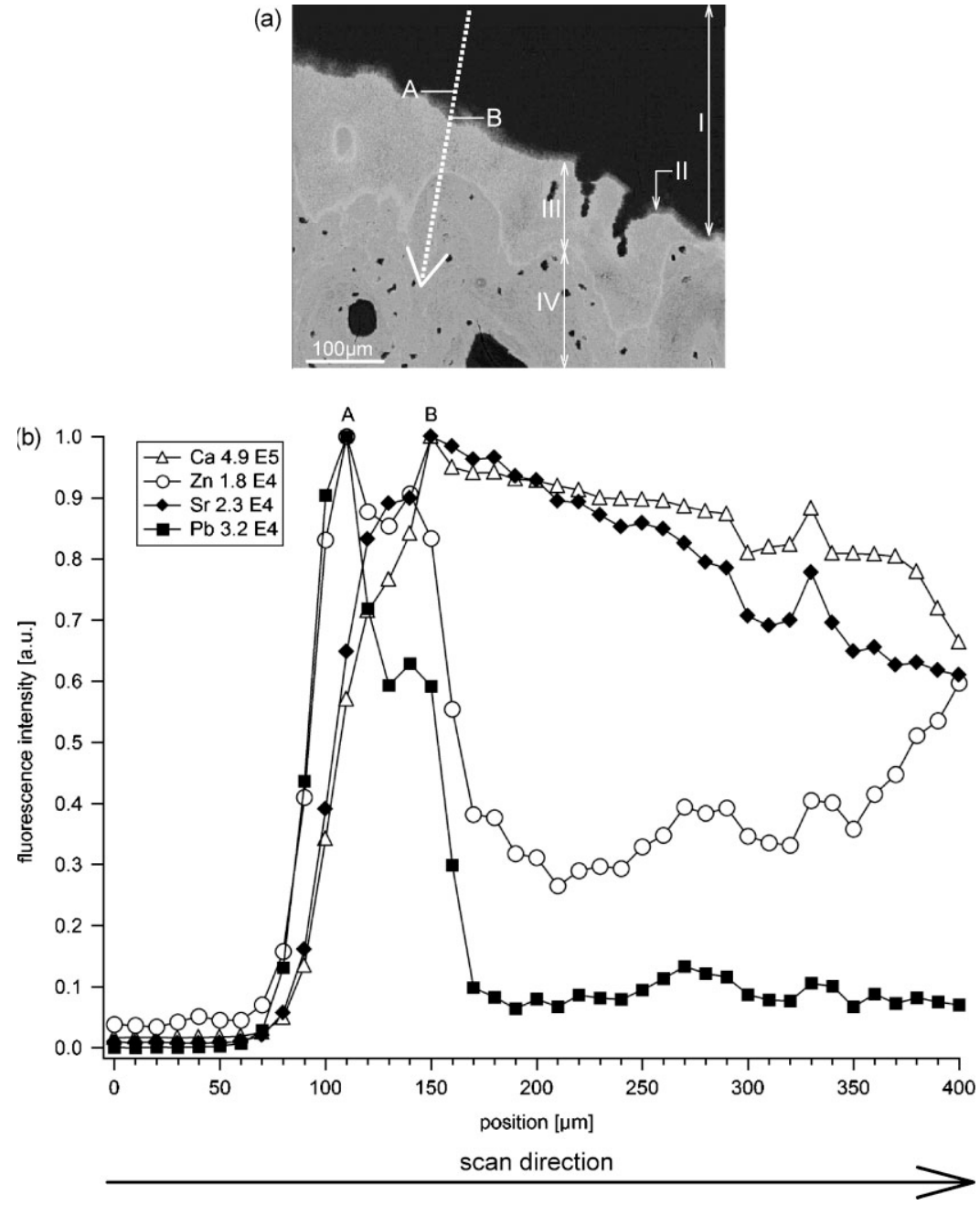

Figure 2. (a) Backscattered Electron (BE) image of the analysed $200 \mu \mathrm{m}$ thick patella sample, showing the calcified areas of the bone section. The performed SR -XRF line scan in conventional geometry, indicated by the arrow (dots correspond to measurement positions) was performed across (I) non-calcified cartilage articular cartilage, (II) the tidemark, (III) calcified cartilage and (IV) subchondral bone. (b) Fluorescence intensity profiles along the scanned line. Maximum fluorescence intensities are normalized to 1 for visualization (absolute intensity values for each element are given in the legend). Positions $A$ and $B$ correspond to the measurement points shown in the BE image.

\section{Combined SR x-ray absorption and fluorescence tomography}

In order to gain information on the elemental distribution in depth of a bone sample, a single object slice of a patella was analysed in tomographic mode at the Fluo-Topo beamline at ANKA. The reconstruction or the transmission image as well as the element specific images of the analysed object slice are shown in Fig. 3. As seen from the Ca image, the photons originating from the inner part of the specimen are heavily absorbed by the sample itself and represent only the outer edges of the analysed bone. Therefore the Ca signal could not be used to image the structure of the bone sample. For a qualitative analysis one can use either the transmission tomograph or the image for Sr to determine the sample shape. By comparing the transmission image with the one for $\mathrm{Sr}$ one can see that $\mathrm{Sr}$ is more or less homogeneously distributed over the analysed slice. In contrast to $\mathrm{Sr}$, increased intensities for $\mathrm{Zn}$ and $\mathrm{Pb}$ are restricted to small zones of the bone. These results confirm that the shifts in the individual intensity maxima, as seen in conventional $-\mathrm{XRF}$, are due to geometric effects and do not represent real elemental distributions. However, in the tomographic mode exact conclusions on the distribution of $\mathrm{Zn}$ and $\mathrm{Pb}$ are very complicated, which is mainly due to the missing Ca information due to self absorption. A way to overcome this problem would be to perform combined x-ray fluorescence, Compton and transmission tomography as proposed by Golosio et al. ${ }^{37}$ By applying this method it would be possible to obtain a quantitative spatial distribution of all the detectable elements in the sample, even in cases of strong absorption effects. Although the results presented are very promising, the reconstruction algorithms are more complicated.

A disadvantage when performing analyses in the tomographic mode is that the information from BE imaging is not accessible for the inner parts of the sample, which does not allow overlaying the results from both methods.

\section{Confocal SR m-XRF}

Results from a representative surface scan in a femoral head 

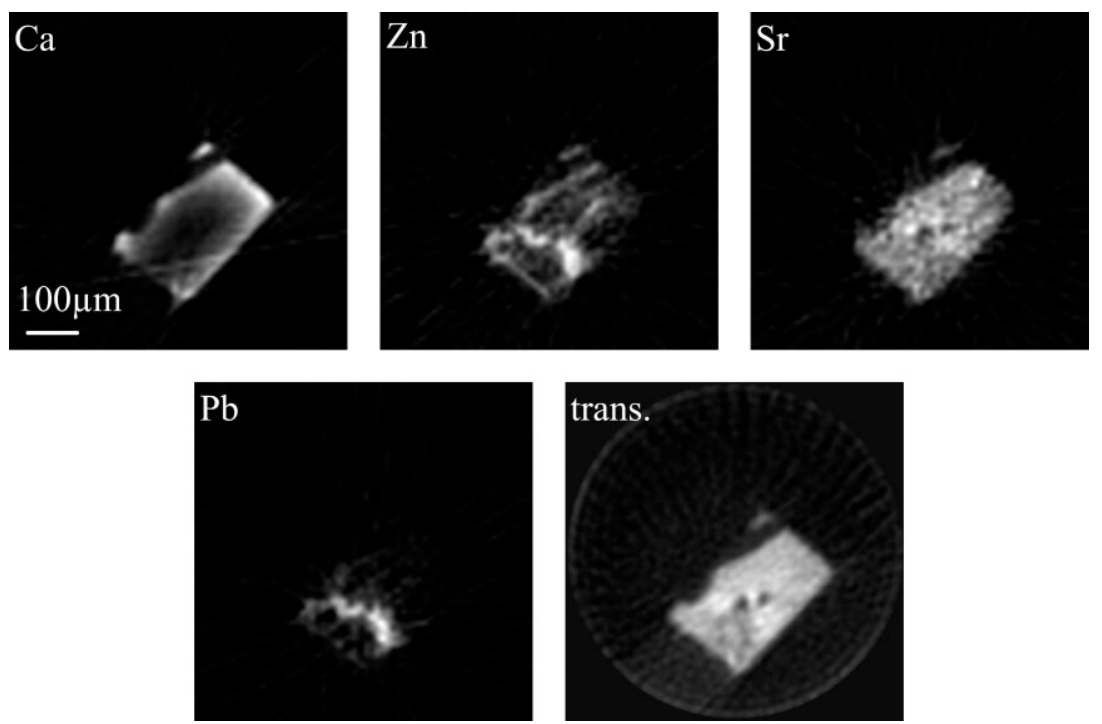

Figure 3. Reconstructed distribution of $\mathrm{Ca}, \mathrm{Zn}, \mathrm{Sr}$, and $\mathrm{Pb}$ as well as of the linear absorption coefficient (trans.) in the analysed object slice of human patella.

sample are shown in Fig. 4. The measurement was performed as an area scan of 65 ð 24 pixels with a measuring time of $7 \mathrm{~s}$ per pixel. As seen from the BE image the scanned region comprised non-calcified cartilage (I), tidemark (II), calcified cartilage (III) and subchondral bone (IV). Comparing the intensity maps with the $\mathrm{BE}$ image it is obvious that the matching of the results from both methods is facilitated owing to the reduced geometric effects when compared to conventional -XRF. Although the spatial resolution of confocal -XRF is still about a factor of 10 less compared to BE imaging, the sample shape can be nicely determined by its $\mathrm{Ca}$ and Sr signal, which allows therefore more precise conclusions on the elemental distributions. Ca was found to be equally distributed over the whole region of calcified tissue, showing slightly increased intensities in calcified cartilage. A similar fluorescence image is observed for Sr. In contrast to the more or less homogeneous distribution of $\mathrm{Ca}$ and $\mathrm{Sr}, \mathrm{Zn}$ and $\mathrm{Pb}$ are inhomogeneously distributed in the scanned region. Increased $\mathrm{Zn}$ intensities were detected at the tidemark and at the border of bone cavities. A similar distribution was found for $\mathrm{Pb}$. The intensity map shows strikingly increased fluorescence intensities at the tidemark. However, the increase in intensity for $\mathrm{Pb}$ at the border of bone cavities was much lower than for $\mathrm{Zn}$.

Quantitative conclusions can be drawn from fluorescence intensity profiles (Fig. 5), which have been extracted from the elemental maps along the marked line in Fig. $4 . \mathrm{Pb}$ and $\mathrm{Zn}$ intensities are dramatically increased in the tidemark region and are almost back to baseline intensities (intensities in subchondral bone) before $\mathrm{Ca}$ intensity levels reach the maximum level. We found distinct changes in the $\mathrm{Pb} / \mathrm{Ca}$ and the $\mathrm{Zn} / \mathrm{Ca}$ intensity ratios between the tidemark (0.06 and 0.2 , respectively) and subchondral bone ( 0.001 and 0.044 , respectively). $\mathrm{Pb}$ intensities at the cavity border are about $10 \%$ of the $\mathrm{Pb}$ intensities at the tidemark, whereas $\mathrm{Zn}$ intensities in this region are about $70-80 \%$ when compared to the tidemark. Interestingly, although the intensity maxima of $\mathrm{Pb}$ and $\mathrm{Zn}$ coincided in the tidemark, considerable differences

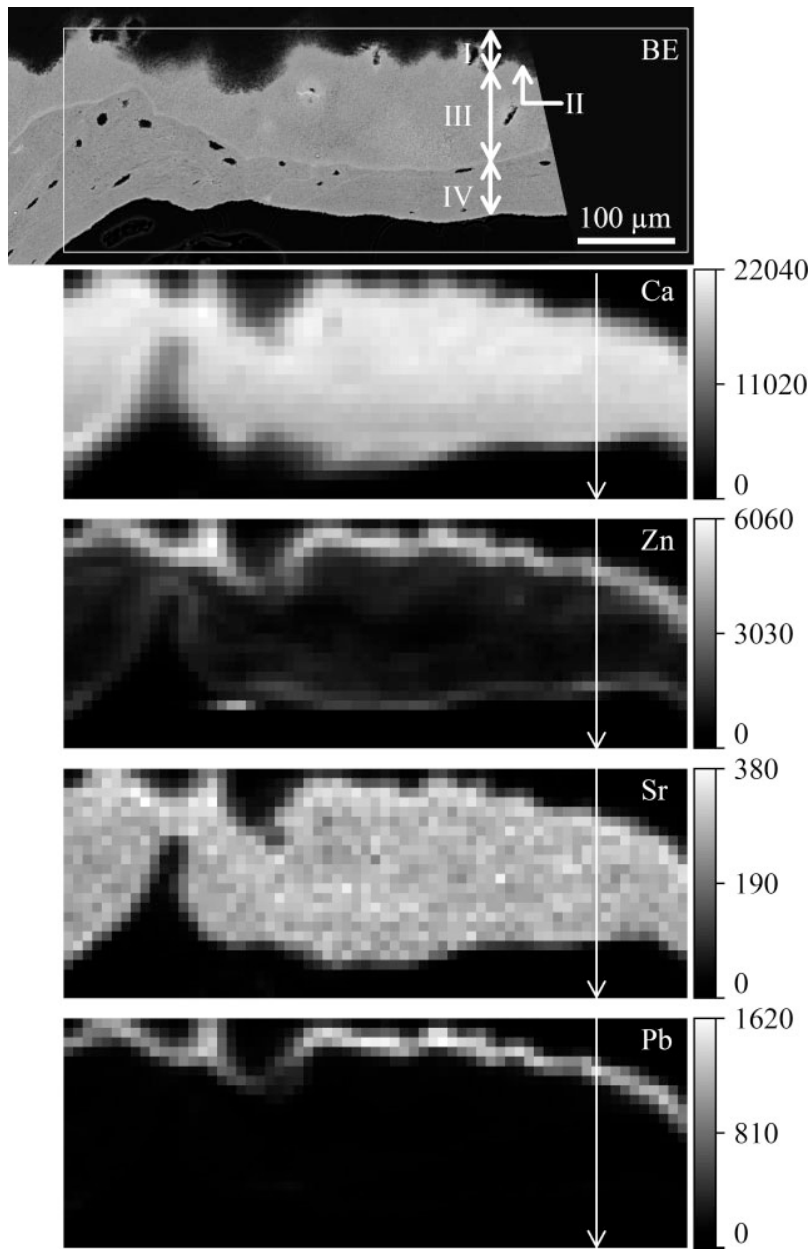

Figure 4. Backscattered electron (BE) image of the femoral head region analysed by confocal SR -XRF. Non-calcified cartilage (I), tidemark (II), calcified cartilage (III) and subchondral bone (IV) can be clearly identified. Elemental maps for $\mathrm{Ca}, \mathrm{Zn}, \mathrm{Sr}$ and $\mathrm{Pb}$ of the scanned region are also shown. Each fluorescence image is scaled from 0 to maximum counts as indicated by the scale bar. A fluorescence intensity profile has been extracted along the marked arrow. The profile is shown in Fig. 5. 
in intensity profiles were found in the subchondral bone. Baseline levels in subchondral bone when compared to tidemark intensities were found to be about $20-40 \%$ for $\mathrm{Zn}$ and below $10 \%$ for $\mathrm{Pb}$.

These findings for $\mathrm{Pb}$ and $\mathrm{Zn}$ were highly consistent and were observed for all scans on paired (femoral head and patella from one subject) as well as single autopsies. The high specificity and reproducibility of $\mathrm{Pb}$ accumulation in adult articular cartilage led us to believe that this could be a general phenomenon.

The results indicate that $\mathrm{Zn}$, an essential element for normal growth of the skeleton, ${ }^{38,39}$ is accumulated in the tidemark and at sites of new bone formation (e.g. border to bone cavity), which is in accordance with the results of earlier studies. ${ }^{40}$

About the mechanisms of $\mathrm{Pb}$ accumulation in the tidemark of articular cartilage, one can only speculate at this point. It has been shown that $\mathrm{Pb}$ interferes with $\mathrm{Ca}^{2 \mathrm{C}}$ signaling in cells by competing for calcium binding sites. ${ }^{41}$ Furthermore, $\mathrm{Pb}$ is able to displace $\mathrm{Ca}^{2 \mathrm{C}}$ by cation exchange processes in the hydroxyapatite crystal, ${ }^{42}$ which could alter the hydroxyapatite crystal and thus effect its material properties. However, to date very few data are available on how $\mathrm{Pb}$ affects bone material properties and bone crystal structure in vivo. The accumulation of $\mathrm{Pb}$ at the tidemark might also have clinical importance, since it is the region of critical mechanical weakness in articular cartilage ${ }^{43}$ where clefts may open due to injuries and osteoarthritis. ${ }^{44}$ Moreover $\mathrm{Pb}$ has been shown to play a role in osteoarthritis, ${ }^{12-14}$ and osteoblasts and chondrocytes seem to be target cells for the toxic effects of $\mathrm{Pb}{ }^{15}$ However, data whether systemic exposure to $\mathrm{Pb}$ affects the risk of developing osteoarthritis is missing.

In order to study the nature of $\mathrm{Pb}$ accumulation and to

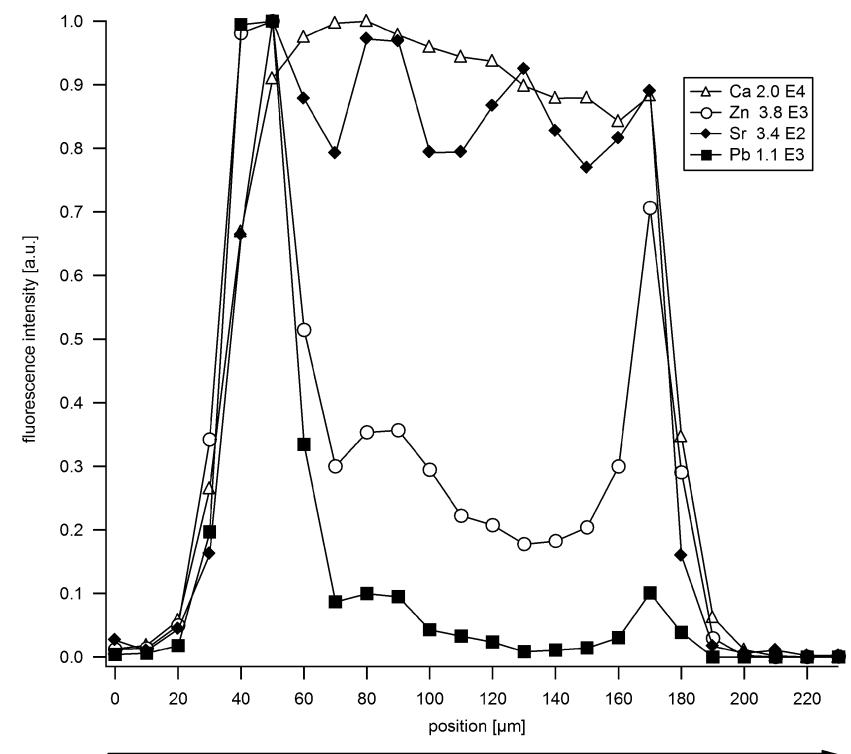

Figure 5. Fluorescence intensities extracted from the data shown in Fig. 4. Maximum fluorescence intensities for each element are normalized to 1 for visualization (absolute intensity values are given in the legend). The shown arrow corresponds to the arrow in the element maps of Fig. 4. exclude artefacts due to sample cutting and polishing, the elemental distribution in a patella sample was studied in 3D.

As for the near-surface scans, non-calcified cartilage, tidemark, calcified cartilage and a small part of subchondral bone were analysed. Figure 6 shows the sum of all 7497 fluorescence spectra recorded during the whole 3D scan (sum spectrum) as well as the spectrum obtained at the position of maximum $\mathrm{Pb}$ intensities (spectrum at $\mathrm{Pb}_{\max }$ ). Owing to the use of the second polycapillary, the detector's field of view is highly restricted to the orbital plane of the synchrotron storage ring, which leads to a drastic reduction in the radiation background and therefore allows measurement times of a few seconds per pixel. As seen from the single spectrum, in cases of no peak overlap a background subtraction is not necessarily required.

The obtained 3D elemental distribution in the analysed volume is shown in Fig. 7.

While the Ca signal decreases rapidly within the first $40-50 \mu \mathrm{m}$ in depth, which is due to self absorption, Sr as well as the coherently scattered peak exhibits nicely the irregular sample shape at the interface between non-calcified and calcified tissue. The results for $\mathrm{Zn}$ and $\mathrm{Pb}$ show the $3 \mathrm{D}$ analogue of what was already seen from the area scan. Maximum intensities are at the tidemark and to some extent a correlation between $\mathrm{Zn}$ and $\mathrm{Pb}$ is seen.

With this 3D experiment it was possible to show that the accumulation of $\mathrm{Zn}$ and $\mathrm{Pb}$ is not a surface effect that might have been introduced by sample cutting and polishing.

\section{CONCLUSIONS}

It has been demonstrated that SR -XRF in different measuring modes is an excellent technique to determine simultaneously the spatial distribution of various (trace) elements such as $\mathrm{Ca}, \mathrm{Sr}, \mathrm{Zn}, \mathrm{Pb}$ in human bone samples with high sensitivity. Both the beamline L at HASYLAB and the Fluo-Topo beamline at ANKA offer sufficient conditions to

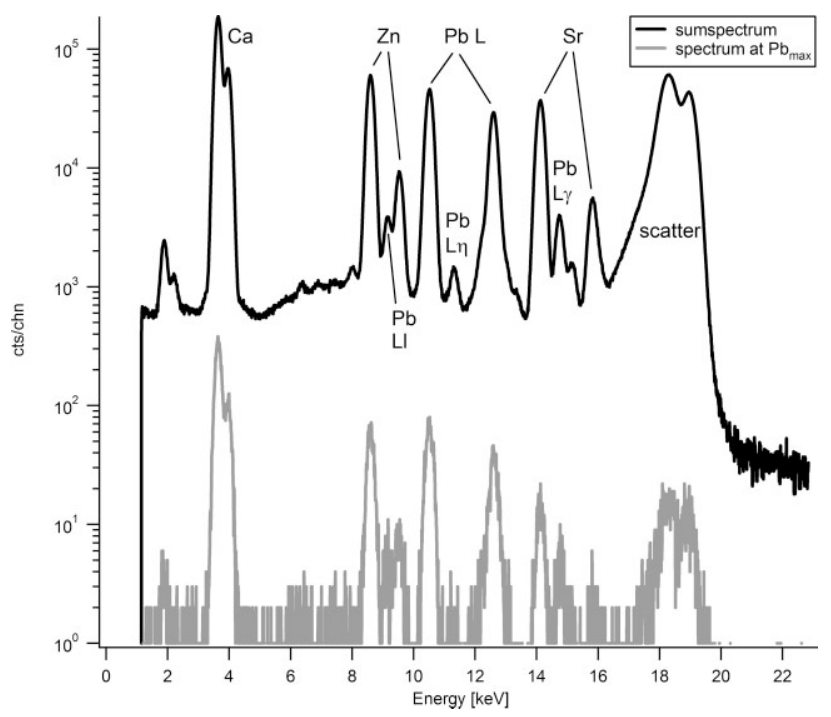

Figure 6. Sum of 7497 spectra (black) as well as a single spectrum at the position of maximum $\mathrm{Pb}$ intensities (gray) as recorded for the 3D scan shown in Figure 7. 

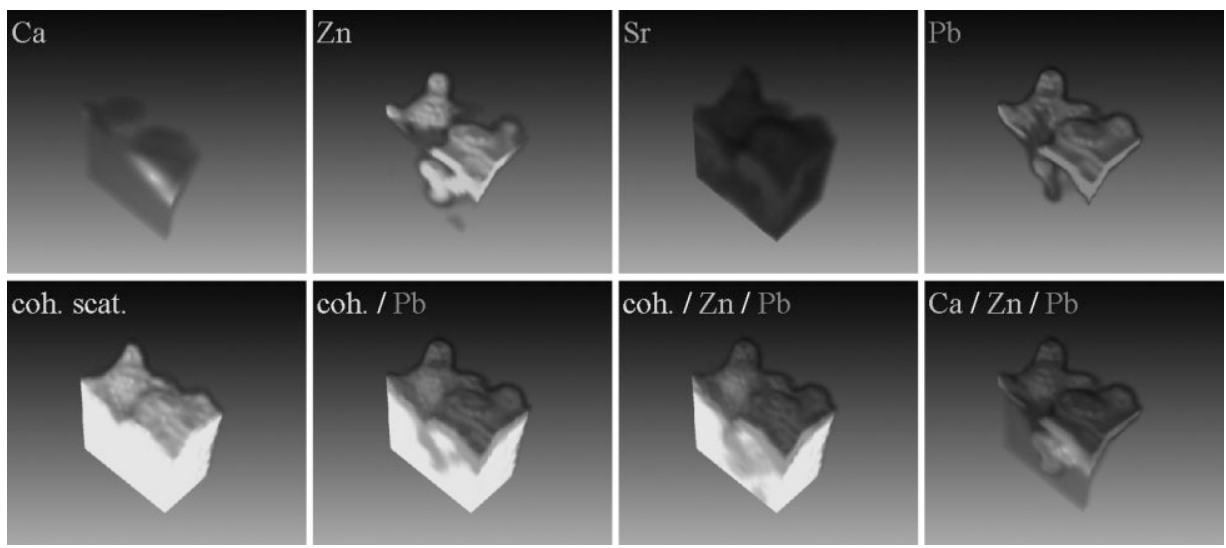

Figure 7. Rendered 3D elemental distribution in a sample volume of 200 ð 200 ð $160 \mu \mathrm{m}^{3}$ obtained from a measured human patella at HASYLAB, beamline L. Calcified tissue in the whole volume can be determined by the coherently scattered signal (white) or by the $\mathrm{Sr}$ signal (blue). $\mathrm{Zn}$ (green) and $\mathrm{Pb}$ accumulation (red) is found at the tidemark. Non-calcified tissue (above the plane of $\mathrm{Pb}$ accumulation) is not shown for better visualization. 0 wing to self absorption, the $\mathrm{Ca}$ map (turquoise) shows only the first few micrometres of the sample.

determine traces of $\mathrm{Pb}$ in matrices containing elements with low and medium atomic numbers in reasonable time.

When measuring $200 \mu \mathrm{m}$ thick bone slices in conventional -XRF geometry, a degradation in spatial resolution was observed. Owing to element- and matrix-specific information depths for different characteristic x-rays, effects of tissue geometry did not allow an exact local correlation among $\mathrm{Ca}, \mathrm{Sr}, \mathrm{Zn}$ and $\mathrm{Pb}$ intensity profiles as well as a precise assignment to BE images, which provide information on the structure of the sample. However, from the conventional SR

-XRF measurements it was possible to conclude that both $\mathrm{Zn}$ and $\mathrm{Pb}$ accumulate around the transition zone between non-calcified and calcified cartilage, where their maximum intensities coincide.

The application of -XRF techniques with 3D capabilities such as SR $x$-Ray fluorescence tomography and confocal SR -XRF helped to unfold elemental distributions and structural features of the specimen. Results from both methods showed that $\mathrm{Zn}$ and $\mathrm{Pb}$ accumulate at thin lines of the bone structure. Furthermore, it was possible to match elemental maps obtained by confocal SR -XRF with BE images and therefore to correlate the elemental distributions to the structural features of calcified human tissue. As a result, it was found that $\mathrm{Pb}$ and $\mathrm{Zn}$ specifically accumulate at the tidemark, the interface between non-calcified and calcified cartilage in joints. Combining lateral and in-depth scanning in confocal geometry it was possible to obtain a three-dimensional elemental distribution in human bone, proving that the accumulation of $\mathrm{Zn}$ and $\mathrm{Pb}$ is not a surface effect. The findings of the specific accumulation of $\mathrm{Pb}$ in the tidemark of normal human adult articular cartilage may lead to further understanding and research on the effects of $\mathrm{Pb}$ on cartilage, bone biology and biomineralization. Since the tidemark plays an important role in osteoarthritis, where tidemark duplication is observed, the presented results may strengthen the conclusions of earlier studies that $\mathrm{Pb}$ is associated with this joint disease.

In conclusion, confocal SR -XRF has several advantages when compared to SR x-ray fluorescence tomography.
Confocal -XRF offers the possibility of sample site selection, in a sense that small sample areas from an otherwise larger specimen can be analysed. Therefore the sample preparation is much easier than it is for -tomography, where sample sizes should not exceed a few hundred micrometers. When performing near-surface scans, a matching of the results with information from other imaging techniques with lower information depths, such as BE imaging, is facilitated. Since the information in the confocal measuring mode is obtained pixel by pixel and not along projection lines, as is the case for tomography, no reconstruction algorithms are required to obtain spatially resolved results. However, a disadvantage of confocal -XRF might be seen in its spatial resolution of about $20 \mu \mathrm{m}$, which is limited by the achievable focal spot sizes of the used capillaries. For SR -tomography special optics such as Kirkpatrick-Baez mirrors or CRLs might be used, offering spot sizes in the low- or even the submicrometre range and therefore leading to improved spatial resolution.

\section{Acknowledgements}

This project was supported by the Austrian Science Fund (FWF) under the project P15740 and by the European Community-Research Infrastructure Action under the FP6-Programmes: 'Structuring the European Research Area' (through the Integrated Infrastructure Initiative 'Integrating Activity on Synchrotron and Free Electron Laser Science'; Contract RII3-CT-2004-506008 (IASFS)).

\section{REFERENCES}

1. Pirkle JL, Brody DJ, Gunter EW, Kramer RA, Paschal DC, Flegal KM, Matte TD. JAMA 1994; 272(4): 284.

2. Vig EK, Hu H. J. Am. Geriatr. Soc. 2000; 48(11): 1501.

3. Wittmers LE Jr, Aufderheide AC, Wallgren J, Rapp G Jr, Alich A. Arch. Environ. Health 1988; 43(6): 381.

4. Rabinowitz MB. Environ. Health Perspect. 1991; 91: 33.

5. Adachi JD, Arlen D, Webber CE, Chettle DR, Beaumont LF, Gordon CL. Calcif. Tissue Int. 1998; 63: 429.

6. Osterode W, Reining G, Manner G, Jager J, Vierhapper H. Thyroid 2000; 10(2): 161.

7. Osterode W, Winker R, Bieglmayer C, Vierhapper H. Bone 2004; 35(4): 942. 
8. Tsaih SW, Korrick S, Schwartz J, Lee ML, Amarasiriwardena C, Aro A, Sparrow D, Hu H. Environ. Health Perspect. 2001; 109(10): 995.

9. Silbergeld EK, Schwartz J, Mahaffey K. Environ. Res. 1988; 47(1): 79.

10. Escribano A, Revilla M, Hernandez ER, Seco C, GonzalezRiola J, Villa LF, Rico H. Calcif. Tissue Int. 1997; 60(2): 200.

11. Carmouche JJ, Puzas JE, Zhang X, Tiyapatanaputi P, CorySlechta DA, Gelein R, Zuscik M, Rosier RN, Boyce BF, O'keefe RJ, Schwarz EM. Environ. Health Perspect. 2005; 113(6): 749 .

12. Slavin RE, Swedo J, Cartwright JJ, Viegas S, Custer EM. Hum. Pathol. 1988; 19(2): 223.

13. Harding NR, Lipton JF, Vigorita VJ, Bryk E. J. Trauma 1999; 47(5): 951.

14. Bolanos AA, Vigorita VJ, Meyerson RI, D'ambrosio FG, Bryk E. J. Trauma 1995; 38(4): 668.

15. Puzas JE, Sickel MJ, Felter ME. Neurotoxicology 1992; 13(4): 783.

16. Han S, Li W, Jamil U, Dargan K, Orefice M, Kemp FW, Bogden JD. Environ. Health Perspect. 1999; 107(8): 657.

17. Hu H, Tosteson T, Aufderheide AC, Wittmers L, Burger DE, Milder FL, Schidlovsky G, Jones KW. Basic Life Sci. 1990; 55: 267.

18. Lindh U, Brune D, Nordberg G. Sci. Total Environ. 1978; 10(1): 31.

19. Schidlovsky G, Jones KW, Burger DE, Milder FL, Hu H. Basic Life Sci. 1990; 55: 275.

20. Aro A, Amarasiriwardena C, Lee ML, Kim R, Hu H. Med. Phys. 2000; 27(1): 119

21. Jones KW, Schidlovsky G, Burger DE, Milder FL, Hu H. Basic Life Sci. 1990; 55: 281.

22. Roschger P, Plenk H Jr, Klaushofer K, Eschberger J. Scanning Microsc. 1995; 9(1): 75.

23. Roschger P, Fratzl P, Eschberger J, Klaushofer K. Bone 1998; 23(4): 319.

24. Gupta HS, Schratter S, Tesch W, Roschger P, Berzlanovich A, Schoeberl T, Klaushofer K, Fratzl P. J. Struct. Biol. 2005; 149(2): 138.

25. Zizak I, Roschger P, Paris O, Misof BM, Berzlanovich A, Bernstorff S, Amenitsch H, Klaushofer K, Fratzl P. J. Struct. Biol. 2003; 141(3): 208.
26. Misof BM, Roschger $\mathrm{P}$, Cosman F, Kurland ES, Tesch W, Messmer P, Dempster DW, Nieves J, Shane E, Fratzl P, Klaushofer K, Bilezikian J, Lindsay R. J. Clin. Endocrinol. Metab. 2003; 88(3): 1150.

27. Falkenberg G, Rickers K. HASYLAB Annual Report, 2002; http: / / www-hasylab.desy.de/science/ annualreports / 2002_report/part1/intern/8522.pdf.

28. Seibersdorf IL. QXAS, Vienna, 1996

29. Janssens K, Proost K, Falkenberg G. Spectrochim. Acta, Part B 2004; 59(10-11): 1637.

30. Simon R, Danilewsky AN. Nucl. Instrum. Methods B 2003; 199: 550.

31. Wegrzynek D, Markowicz A, Bamford S, Chinea-Cano E, Bogovac M. Nucl. Instrum. Methods Phys. Res., Sect. B 2005; 231: 176.

32. Jernstrom J, Eriksson M, Osan J, Tamborini G, Törok S, Simon R, Falkenberg G, Alsecz A, Betti M, J. Anal. At. Spectrom. 2004; (19): 1428.

33. Data Acquisition for X-ray Microprobe, Computer Manual Series No. 17. IAEA: Vienna, 2002.

34. Kak AC, Slaney M. Principles of Computerized Tomographic Imaging. IEEE Press: New York, 1988.

35. Zoeger N, Wobrauschek P, Streli C, Pepponi G, Roschger P, Falkenberg G, Osterode W. X-Ray Spectrom. 2005; 34(2): 140.

36. Zoeger N, Roschger $P$, Hofstaetter JG, Jokubonis C, Pepponi G, Falkenberg G, Fratzl P, Berzlanovich A, Osterode W, Streli C, Wobrauschek P. Osteoarthr. Cartil. 2006; 14(9): 906.

37. Golosio B, Simionovici A, Somogyi A, Lemelle L, Chukalina M, Brunetti A. J. Appl. Phys. 2003; 84: 145.

38. Calhoun NR, Smith JCJ, Becker KL. Clin Orthop Relat Res. 1974; 103: 212.

39. Nishi Y. J. Am. Coll. Nutr. 1996; 15(4): 340.

40. Gomez S, Rizzo R, Pozzi-Mucelli M, Bonucci E, Vittur F. Bone 1999; 25(1): 33

41. Pounds JG, Long GJ, Rosen JF. Environ. Health Perspect. 1991; 91: 17.

42. Mavropoulos E, Rossi AM, Costa AM, Perez CA, Moreira JC, Saldanha M. Environ. Sci. Technol. 2002; 36(7): 1625.

43. Kumar P, Oka M, Nakamura T, Yamamuro T, Delecrin J. Nippon Seikeigeka Gakkai Zasshi. 1991; 65(11): 1070.

44. Landells JW. J. Bone Joint Surg. Br. 1957; 39-B(3): 548. 